Available online on 15.01.2021 at http://jddtonline.info
(C) 2011-21, publisher and licensee JDDT, This is an Open Access article which permits
unrestricted non-commercial use(CC By-NC), provided the original work is properly cited
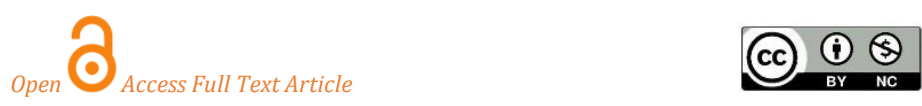

Review Article

\title{
Niosomes: A Novel Carrier Drug Delivery System
}

\author{
Kauslya Arumugam ${ }^{1 *}$, Borawake Payal D ${ }^{1}$, Shinde Jitendra V2, Chavan Rajashree S3 \\ 1 Department of Pharmaceutics, Pune District Education Association's, Seth Govind Raghunath Sable College of Pharmacy, Saswad, Pune,
} Maharashtra, India

2 HOD, Department of Pharmaceutics, Pune District Education Association's, Seth Govind Raghunath Sable College of Pharmacy, Saswad, Pune, Maharashtra, India

3 Principal, Pune District Education Association's, Seth Govind Raghunath Sable College of Pharmacy, Saswad, Pune, Maharashtra, India

\section{Article Info:}

Article History:

Received 24 Oct 2020;

Review Completed 18 Dec 2020

Accepted 23 Dec 2020;

Available online 15 Jan 2021

Cite this article as:

Kauslya A, Borawake PD, Shinde JV, Chavan RS,

Niosomes: A Novel Carrier Drug Delivery System,

Journal of Drug Delivery and Therapeutics. 2021;

11(1):162-170

DOI: http://dx.doi.org/10.22270/jddt.v11i1.4479

*Address for Correspondence:

Kauslya Arumugam, Department of Pharmaceutics, Pune District Education Association's, Seth Govind Raghunath Sable College of Pharmacy, Saswad, Pune, Maharashtra, India

\section{Abstract}

Niosomes are a novel drug delivery system, in which the medication is encapsulated in a vesicle. The vesicle is composed of a bilayer of non-ionic surfactants. Niosomes are mostly preferred than liposomes because they are stable and cost effective. Niosomes potentiate the pharmacological action of the drug molecules by delaying the clearance of the drug from the circulation, protecting the drug from biological environment and restricting the effects only to the target cells. In novel drug delivery it has applications on treatment of cancer, used as a carrier in haemoglobin, delivery of the peptide drugs through oral route, in treatment of leishmaniasis, in ophthalmic delivery and as carrier in dermal drug delivery. This review article focuses on the composition, advantages, types of niosomes, methods of preparation, characterization and application of the vesicular system.

Keywords: Niosomes, Composition, Types, Method of preparation, Factors affecting, Application.

\section{INTRODUCTION:}

Paul Ehrlich began the history of controlled distribution in 1909 when he foresaw a method for the delivery of drugs that would specifically target diseased cells. Drug directing can be characterised as the capacity to precisely guide a beneficial product to the target location of operation with next to no non-target tissue interference [1]. The drug is encompassed in a vesicle in the drug delivery process of niosomes. The lipid membrane consists of a bilayer of active non-ionic surface elements and therefore the designation of niosomes [2, 3, 4].Niosomes are non-ionic surface-active agent vesicles which may be non-heritable by association of artificial non-ionic surfactants, with or while not incorporation of cholesterol or alternative lipids [5]. They are sac systems almost like liposomes that might be secondly used as transporter of amphipathic and lipotropic drugs. One in every of the rationale for making ready niosomes is assumed greater chemical strength of the surface-active agent than that of phospholipids, that are employed in the preparation of liposomes. Due to the existence of organic compound bond, phospholipid is simply hydrolysed [6] (Figure 1).

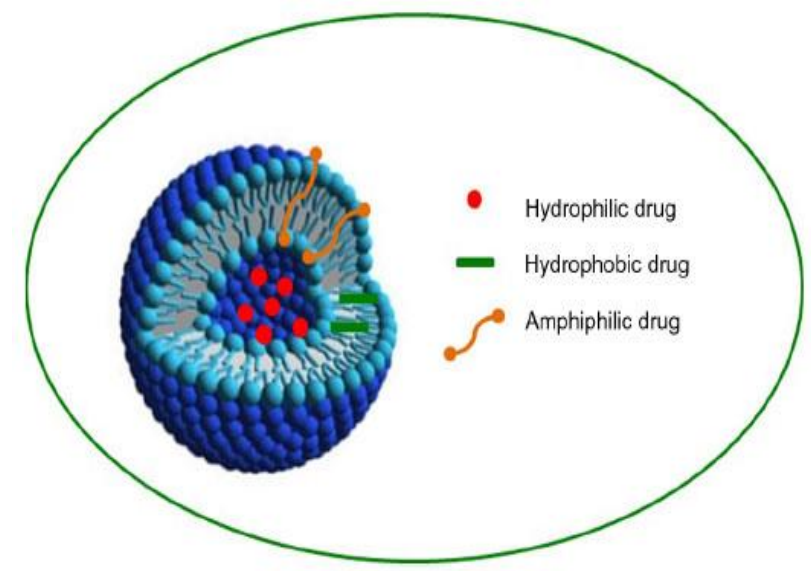

Figure 1: Structure of Niosome

Unreliable dependableness arising from the employment of emulsifier in liposomes leads to extra issues and has led scientist to look for vesicles ready from alternative material, like non-ionic surface- active agents. Niosomes are 
optimistic vehicle for drug delivery and being non-ionic; it's less cytotoxic and improves the therapeutic index of drug by prescribing its action to focus on target cells. In niosomes, the vesicles forming amphiphile may even be a non-ionic surface-active agent like Span -sixty which is typically stabilized by addition of cholesterol and tiny quantity of anionic surface-active agent such as dicetyl-phosphate [7]. Niosomes are microscopic lamellar structures of the size vary between ten to $1000 \mathrm{~nm}$. The niosome comprises of non-immunogenic, perishable and biocompatible surfaceactive agents. The utilization of sac (lipid vesicles and nonionic surface-active agent vesicles) systems in cosmetics and for therapeutic response might provide several advantages which are-

1) Higher patient compliance as compared with oily dosage forms.

2) The vesicles might act as a depot, cathartic the drug throughout a controlled manner.

3) Accommodate drug molecules with a wide good vary of solubilities [8].

They show high stability and alter the transportation of drug at desired site during controlled or sustained manner. In current years, the potential of niosomes as a drug porter has been broadly studied. Numerous class of non-ionic surfaceactive agent square leads to the evolution of niosomes and alter the defence of an oversize variety of medicine (drug) with a decent vary of solubility. The constitution, dimensions, variety of lamellae, and surface electric charge of niosomes are usually varied and enhanced to strengthen the performance of niosomes for drug transportation. The intention of preparing this review is to confer the basics of niosome preparation and characterization with the outline of their use in drug delivery. This review article will furnish an outline of the increasing curiosity on niosomes in the field study of medication delivery [9].

\section{SALIENT FEATURES OF NIOSOMES:}

- Niosomes are osmotically stable and can entangle the solute and increase the firmness of entangled drug.

- Niosomes are non-ionic surfactants that are biocompatible, non-immunogenic and biodegradable.

- Niosomes possess a framework which comprises of deliquescent and hydrophobic largely along so allows the drug molecules with a large vary of solubility.

- Labile and sensitive medication can be easily delivered by niosomes.

- Niosomes are usually flexible structurally so they can be designed according to the desired situation.

- Availability of the drug at the particular site is better, just by securing the drug from biological environment.

- Solubility and oral bioavailability of sparingly soluble drugs are improved by niosomes and also skin penetrability of drugs which are applied topically is enhanced $[10,11,12]$.

\section{ADVANTAGES:}

- Reduced side effects and shows maximum duration of action.

- Patient compliance is more compared to other delivery system.
- Quantity of drug used is very less for achieving its desired effect.

- Active ingredient or constitutent present in the preparation is protected by bilayer from various factors present inside and outside the body.

- Act as depot formulation, thus the drug is released in a controlled manner.

- Drug is protected from first pass metabolism and gastrointestinal degradation.

- Possess stable structure even in emulsion form.

- Niosomes are available in oral, topical as well as parenteral routes $[10,13,14]$.

\section{DISADVANTAGES:}

- Time consuming process.

- Specialized equipments are required for processing.

- Limited shelf life due to-1) Fusion

2) Aggregation

3) Leakage of entrapped drugs

4) Hydrolysis of encapsulated drugs.

- Physically unstable $[15,16,17]$.

\section{COMPOSITION OF NIOSOMES:}

The vital components used in the niosome formulation are:

- Non-ionic surfactants

- Cholesterol

- Charge inducer

- Hydration medium

\section{1) Non-ionic surfactants:}

The primary component used in the formulation of the noisome is the surface-active agent. They are amphiphilic in nature comprising a polar head and a non-polar tail [18]. These agents are more stable, compatible and less toxic when compared to other surfactants such as anionic, cationic and amphoteric surfactants because they do not carry any charge. These agents cause less haemolysis and irritation to cellular surfaces. They can be used as wetting agents and emulsifiers. The important characteristic of nonionic surfactant is that they inhibit p-glycoprotein and thus enhance the absorption and targeting [19] of anticancer drugs (example-doxorubucin, daunorubicin, curcumin, morusin) [20, 21, 22, 23], steroids (example-hydrocortisone) [24], HIV-protease inhibitor (example-ritonavir) [25], cardiovascular drugs (example-digoxin, beta-blockers) [26].

Non-ionic surfactant exhibit high interfacial activity and are comprised of both polar and non-polar groups/segments. The bilayer vesicles formation depends on hydrophiliclipophilic balance (HLB) scale, chemical structure of components and critical packing parameter (CPP).The entrapment efficiency of drug are usually altered by chain length and size of hydrophilic head group of non-ionic surfactant. Non-ionic surfactant with larger alkyl chain shows higher entrapment efficiency. The Tween sequence of surfactants possessing an extended alkyl chain and an outsized hydrophilic moiety together with cholesterol during a ratio $1: 1$ have the very best entrapment efficiency of water soluble drugs. The HLB value of a surfactant plays a 
vital role in managing drug entrapment of the vesicle it forms $[27,28,29]$.

Critical packing parameter (CPP) value of a surfactant can be calculated from the area of the polar head group and volume and length of the non-polar group. Using CPP values the type of vesicle going to be formed can be determined (Figure 2) and also by the calculation of CPP using certain formula [30].

$$
\mathrm{CPP}=\mathrm{V} / \mathrm{Ic} \mathrm{X} \mathrm{a}_{0}
$$

Where, $\mathrm{V}=$ Volume of non-polar group

Ic $=$ Critical non-polar group length

$\mathrm{a}_{0}=$ Area of polar head group

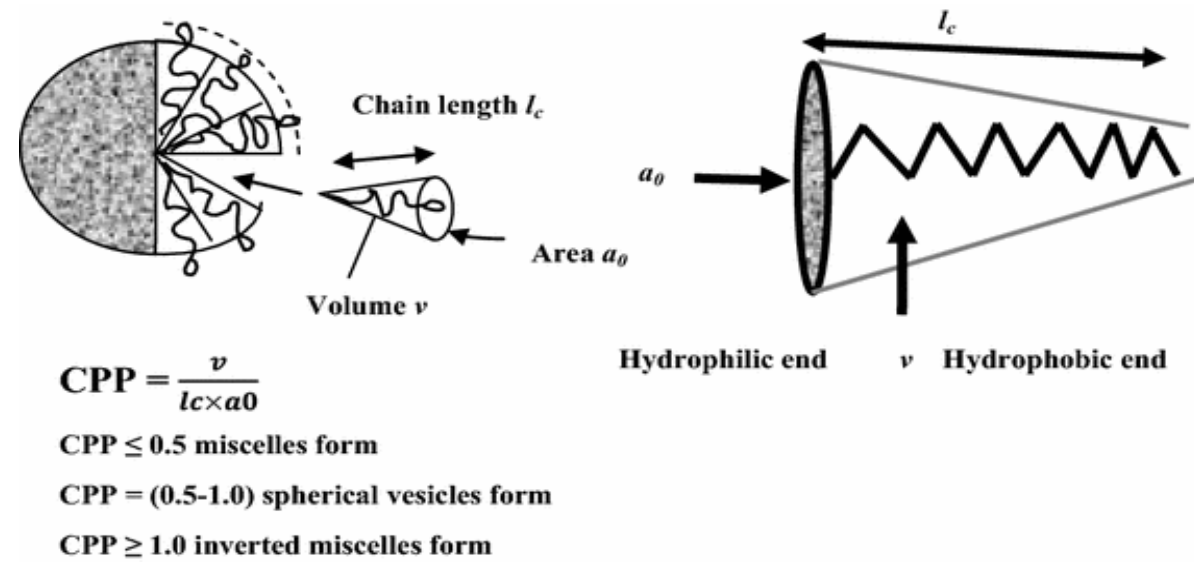

Figure 2: Critical Packing Parameter

\section{2) Cholesterol:}

Cholesterol is a waxy steroid derivative found within the cell membrane that is principally employed in the preparation of niosomes [31]. Leakiness of the cell membrane is decreased by stabilizing the membrane by incorporating cholesterol into the bilayer constitution of niosomes; this frequently increases the entrapment efficiency of the niosomes [32]. Cholesterol is usually added to non-ionic surfactants to give hardness and proper direction/adjustment to niosomal bilayer [33]. Cholesterol is renowned to get rid of gel to liquid phase transition of niosomal system leading to niosomes that are less leaky [34].

\section{3) Charge inducers:}

Charge inducers are added in the preparation to increase the stability of niosomes by electrostatic repulsion to avoid coalescence. The negatively charged molecules mostly used are diacetyl phosphate (DCP) and phosphotidic acid. Similarly positively charged inducers used in niosomal preparations are stearyl amine (STR) and stearylpyridinium chloride. A concentration of 2-5 mole percentages of charged inducers is bearable because higher concentration can hamper the niosome formation $[35,36]$.

\section{4) Hydration medium:}

The most commonly used hydration medium in the preparation of niosome is phosphate buffer. These phosphate buffers are used at various $\mathrm{pHs}$. The actual $\mathrm{pH}$ of the hydration medium depends on the solubility of the drug being encapsulated [37].

\section{TYPES OF NIOSOMES:}

The different types of niosomes can be classified as follows: (Figure 3).
1) Multilamellar vesicles (MLV)
2) Large unilamellar vesicles (LUV)
3) Small unilamellar vesicles (SUV)

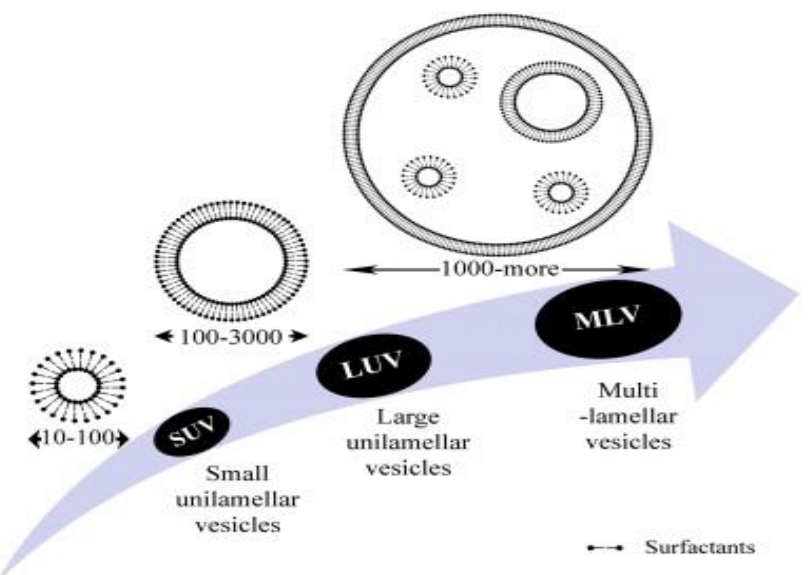

Figure 3: Types of Niosomes

1) Multilamellar vesicles (MLV):

Multilamellar vesicles are most widely niosomes. The size of the vesicles range approximately $0.5-10 \mu \mathrm{m}$ diameter. The method of preparation of the vesicles is easy and it is mechanically stable upon storage for longer periods. It usually consists of number of bilayer surrounding the aqueous lipid component separately. These miltilamellar vesicles are highly suited as drug carrier for lipophilic compounds.

\section{2) Large unilamellar vesicles (LUV):}

Large unilamellar type of niosomes have high aqueous/ liquid compartment ratio, so that larger volumes of bioactive materials can be entrapped with a very economical use of membrane lipids. The size of large unilamellar vesicles are in the range of 100-3000 nm length.

\section{3) Small unilamellar vesicles (SUV):}

Small unilamellar vesicles are mostly prepared from multilamellar vesicles by sonication method. It has been reported that the size of the small unilamellar vesicles are in the range of $10-100 \mathrm{~nm}[38,39]$. 


\section{METHOD OF PREPARATION:}

1) Hand shaking method (Thin film hydration technique)

2) Micro fluidisation

3) Reverse Phase Evaporation (REV)

4) Ether Injection Method

5) Trans-membrane pH-gradient (inside acidic)

6) The Bubble Method

7) Sonication

8) Multiple extrusion method

9) Formation of niosomes from proniosomes

\section{1) Hand shaking method (Thin film hydration} technique):

In hand shaking method, round bottom flask is used in which non-ionic surfactant and cholesterol are dissolved in a volatile organic solvent (such as diethyl ether, chloroform, or methanol). The organic solvent is removed using rotary evaporator at room temperature $\left(20^{\circ} \mathrm{C}\right)$ leaving a thin layer of solid mixture which is deposited on the wall of the flask. With gentle agitation the dried surfactant film is hydrated with aqueous phase containing drug at $50-60^{\circ} \mathrm{C}$. By this method multilamellar niosomes are formed $[40,41]$.

\section{2) Micro fluidisation:}

Micro-fluidisation is a technique in which unilamellar vesicles of defined size distribution are prepared. It is based on submerged jet principle in which two fluidized streams interact at ultra-high velocities $(100 \mathrm{ml} / \mathrm{min})$, in precisely defined micro channels within the interaction chamber. The impingement of thin liquid sheet along a common front is arranged in such a way that the energy supplied to the system remains within the area where niosomes are formed. Niosomes formed by this method have greater uniformity, smaller size and better reproducibility $[42,43]$.

\section{3) Reverse Phase Evaporation (REV):}

In reverse phase evaporation, the cholesterol and surfactant is taken in the ratio 1:1 ratio. The above mixture is dissolved in ether and chloroform mixture. Drug is dissolved in aqueous phase. Both the mixture is sonicated at the temperature $4-6^{\circ} \mathrm{C}$. The suspension of niosomes is diluted in the PBS at $60^{\circ} \mathrm{C}$ using water bath for 10 minutes, which yields the niosomes. PBS is again added to the obtained product and sonicated at low pressure and temperature is maintained at $40-45^{\circ} \mathrm{C}$ and organic phase is removed at this temperature. The resultant suspension is diluted with PBS and heated on water at $60^{\circ} \mathrm{C}$ to 10 minutes to yield niosomes $[44,45]$.

\section{4) Ether injection method:}

In ether injection method, the niosomes are prepared by introducing a solution of surfactant which is dissolved in diethyl ether (volatile organic solvent) into warm water which is maintained at $60^{\circ} \mathrm{C}$. The surfactant mixture in ether is injected into an aqueous solution of material with the help of 14-gauge needle. Single layered vesicles are formed by vapourization of ether (volatile organic solvent) [46].

\section{5) Trans-membrane $\mathrm{pH}$ gradient (inside acidic):}

In this method, the surfactant and cholesterol is mixed/ blended in round bottom flask and dissolved in chloroform. On the wall of the flask, a thin film is formed by evaporating the chloroform under reduced pressure. Hydration of film is done by vortex mixing with $300 \mathrm{mM}$ citric acid ( $\mathrm{pH} 4.0)$. To the above niosomal suspension, aqueous solution containing $10 \mathrm{mg} / \mathrm{ml}$ of drug is added and vortexed. The $\mathrm{pH}$ of the sample is adjusted to 7.0-7.2 by adding $1 \mathrm{M}$ disodium phosphate and this mixture is heated at $60^{\circ} \mathrm{C}$ for 10 minutes. Multilamellar vesicles are produced by this method [47, 48, 49].

\section{6) The Bubble method:}

The bubble method is a novel technique in which the niosomes are prepared without using organic solvents. The bubbling unit is used in this method. This unit consist of round bottom flask with 3 necks positioned in water bath by which the temperature is controlled. Water-cooled reflux is placed in first neck, thermometer is placed in second neck and the nitrogen is passed through the third neck. Cholesterol and surfactant are mixed together in buffer solution ( $\mathrm{pH}-7.4)$ at $70^{\circ} \mathrm{C}$. High shear homogenizer is used for mixing the solution for 15 seconds, and then this solution is immediately bubbled at $70^{\circ} \mathrm{C}$ by the use of nitrogen gas [50,51] (Figure 4).

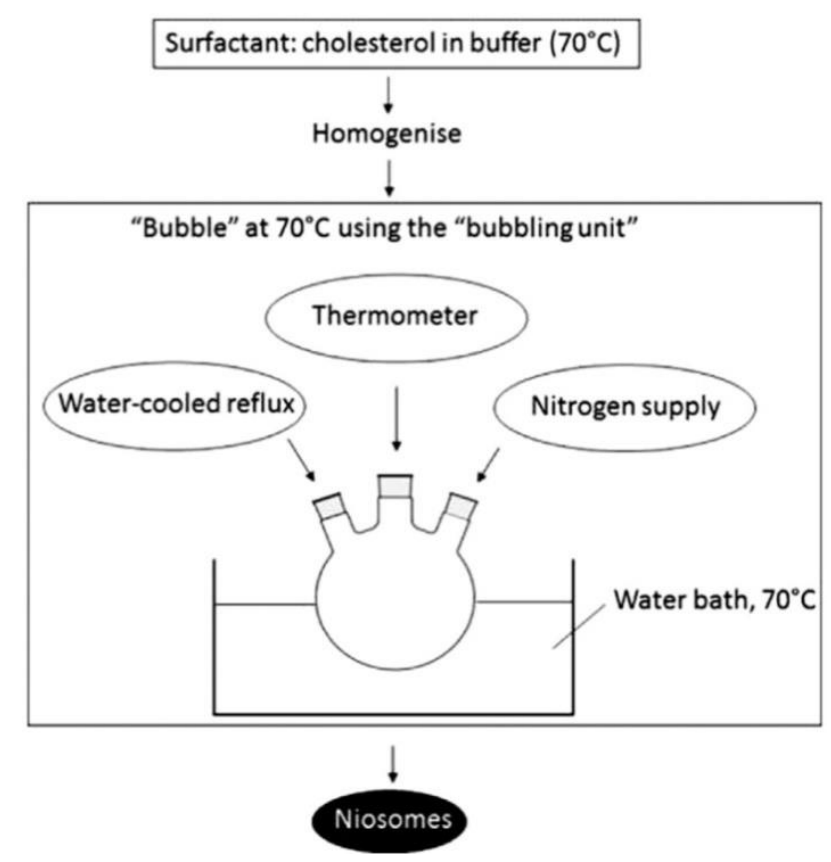

Figure 4: The bubble method

\section{7) Sonication:}

Sonication is one of the conventional method for the preparation of niosomes. In this method, the drug solution is prepared by dissolving drug in buffer. Then this buffer drug solution is added the mixture of the non-ionic surfactant at optimized ratio. The desired niosomes are obtained by sonicating the mixture at specific frequency, temperature and time. It is one of the easy way in which the particle size of the niosomes can be controlled. This method can be used to decrease the diameters of niosomes with narrow size distribution. Probe sonicators can also be used but they involve high levels of energy. Due to this it leads to sudden increase in temperature and discharge of titanium [52].

\section{8) Membrane Extrusion Method:}

In this method the surfactant, cholesterol and diacetyl phosphate is mixed in chloroform. Then this chloroform mixture is evaporated to obtain thin film. Hydration of thin film is done with aqueous drug polycarbonate membrane. Solution and resultant suspension is extruded through this membrane (which consist of 8 passages). Required size of the niosomes is also obtained by this method $[53,54]$. 


\section{8) Formation of niosomes from proniosomes:}

By addition of aqueous phase with drug to the preniosomes with short agitation at a temperature greater than mean transition phase temperature of the surfactant results in the formation of the niosomes [55].

$$
\mathrm{T}>\mathrm{Tm}
$$

Where,

\section{$\mathrm{T}=$ Temperature}

$\mathrm{Tm}=$ Mean phase transition temperature

Blazek-Walsh A.I et al has described the formulation of niosomes from maltodextrin based preniosomes. This formulation furnishes rapid reconstitution of niosomes with the minimal left over/ residual carrier. Free flowing powder of formulation was obtained by drying the slurry of maltodextrin and surfactant, which could be rehydrated by addition of warm water $[56,57]$.

\section{SEPARATION OF UNENTRAPPED DRUG:}

\section{1) Dialysis:}

The aqueous niosomal suspension is dialyzed in dialysis tubing by using phosphate buffer or glucose solution or normal saline.

\section{2) Gel Filtration:}

The unentrapped drug in the niosomal suspension is removed by gel filtration using Sephadex-G-50 column and elution is done with phosphate buffered saline or normal saline.

\section{3) Centrifugation:}

In centrifugation, the niosomal suspension is centrifuged and the supernatant liquid is separated. Niosomal suspension free from unentrapped drug is obtained by washing the pellet and the resuspended solution $[58,59]$.

\section{NIOSOMES VERSUS LIPOSOMES:}

The liposomes and niosomes are almost similar in nature. The phospholipids used in liposomes are not stable in nature; whereas niosomes are made up of non-ionic surfactants which are stable. Niosomes are prepared from unchanged single chain non-ionic surfactant, whereas liposomes are prepared from double-chain phospholipids. The size of niosomes ranges from $10-100 \mathrm{~nm}$ and liposomes from $10-300 \mathrm{~nm}$. According to cost, the niosomes are economically cheap compared to liposomes [60].

\section{FACTORS AFFECTING THE NIOSOME FORMATION:}

\section{1) Drug:}

The physico-chemical properties of encapsulated drug directly affect the charge and rigidity of the niosomal bilayer.
The vesicle size of the niosomes is improved by entrapping the drug inside the niosomes, also by interaction of solute with head groups of surfactants. Enhancement of charge and mutual repulsion between the bilayers of surfactant increases the vesicle size. Degree of entrapment is also affected by the Hydrophilic-Lipophilic balance of the drug $[61,62]$.

\section{2) Resistance of osmotic stress:}

The addition of hypertonic salt solution to the niosomal suspension leads the reduction in diameter of niosomes. Again after the addition of hypotonic salt solution, initially it leads to slow release with slight swelling of the vesicles due the inhibition of elution fluid from vesicles. The release becomes faster due to mechanical loosening of vesicle structure under osmotic stress [63].

\section{3) Temperature of hydration medium:}

Temperature of hydration medium plays a vital role in formation of vesicle. This affects their shape and size. The temperature maintained should be above the gel to liquid phase transition temperature of the system. Changes in the vesicle shape are also observed due to the temperature. It also affects the assembly of surfactants into vesicles. Vesicle structure and yield is affected by the volume of hydration medium and duration of the lipid film [27, 64].

\section{4) Cholesterol content:}

Cholesterol affects the physical properties and structure of the niosomes. The structure is affected due the presence of non-ionic surfactants. Cholesterol is present in biological membranes it also affects the membrane properties like ion permeation, aggregation, fusion processes, size, shape, elasticity and enzymatic activity. Addition of cholesterol leads to change in fluidity of niosomes. Cholesterol plays an important role during preparation of niosomes because it provides rigidity to vesicles, which is very important during severe stress conditions. The amount of cholesterol to be added depends on the HLB value of the surfactants. As the HLB value increases above 10, the amount of cholesterol should also be increased in order to remunerate for the larger head groups [65].

Change in HLB value has impact on noisome formulation (Table 1). Inclusion of cholesterol in niosomes increases the hydrodynamic diameter and entrapment efficiency. At high cholesterol concentration, the gel state is transformed to a liquid ordered phase. An increase in cholesterol content of the bilayers results in a decrease in the release rate of encapsulated material and thereby increases the rigidity of the bilayers obtained [66].

Table 1: HLB value and their impact on niosome formation.

\begin{tabular}{|l|l|}
\hline HLB Value & Impact on niosome formation \\
\hline$>6$ & Need to add cholesterol in formation of bilayer formation. \\
\hline $1.7-8.6$ & Decreases entrapment efficiency of niosomes. \\
\hline $14-16$ & Does not produce niosomes. \\
\hline 8.6 & Increases entrapment efficiency of niosomes. \\
\hline Lower value & Need to add cholesterol to increase stability. \\
\hline
\end{tabular}




\section{5) Amount and type of surfactant:}

The mean size of niosomes increases proportionally with increase in the HLB surfactants like Span 85 (HLB 1.8) to Span 20 (HLB 8.6) because the surface free energy decreases with an increase in hydrophobicity of surfactant. The bilayers of the vesicles are either in the liquid state or in gel state, depending on the temperature, the type of surfactant and the presence of other components like cholesterol. Alkyl chains are present in a well-ordered structure in the gel state, while in the liquid state, the structure of the bilayers is more disordered. The surfactants and lipids are characterized by the gel-liquid phase transition temperature (TC). Phase transition temperature (TC) of surfactant also affects the entrapment efficiency i.e. Span 60 having higher TC, provides better entrapment [67].

\section{6) Membrane Composition:}

Addition of various additives along with surfactants and drugs leads to the stable formation of niosomes. Niosomes formed have a variety of morphologies and their permeability/porousness and stability properties will be altered by manipulating membrane characteristics by totally different additives. Just in case of polyhedral niosomes formed from $\mathrm{C} 16 \mathrm{G} 2$, the shape of these polyhedral niosome remains unaffected due to the addition of low quantity of solution of solulan C24 (cholesterol poly-24-oxyethylene ether), that prevents aggregation due to development of steric [68].

\section{CHARACTERIZATION OF NIOSOMES:}

\section{1) Entrapment Efficiency:}

The entrapment efficiency (EE) of vesicular systems can be defined as the amount of active substances loaded within the niosomal structure. It can be expressed as:

$$
\mathrm{EE}=\frac{\text { Amount entrapped }}{\text { Total amount }} \times 100
$$

where, the "total amount" is the total amount of drug in the prepared in the niosomal formulation. The entrapment efficiency is determined spectrophotometrically by using UV- visible spectrophotometer. In case of genetic material, gel electrophoresis is done followed by UV densitometry. In addition, the entrapment efficiency can also be fluorometrically evaluated using a hydrophilic fluorescent [69].

\section{2) Vesicle size and shape:}

The shape of niosomal vesicles is assumed to be spherical, and their mean diameter can be determined by using laser light scattering method. Also, the diameter of these vesicles can be determined by using electron microscopy, molecular sieve chromatography, ultracentrifugation, photon microscopy and optical microscopy and freeze fracture electron microscopy. Freeze thawed niosomes increases the vesicle diameter, which might lead to the fusion of vesicles during the cycle [49].

\section{3) In-vitro release:}

In in-vitro release study dialysis membrane method is generally used. In this method small amount of niosomes are taken into dialysis bag and are tied at both the ends. Another beaker containing suitable dissolution media is maintained at $37{ }^{\circ} \mathrm{C}$ and the dialysis bag is put into the dissolution medium and stirred by a magnetic stirrer. A sample solution is taken from the beaker at specified time intervals and replaced with fresh dissolution media. The samples were analyzed for the concentration of drug at specified wave length reported in the respective monograph of that particular drug [70].

\section{4) Number of lamellae:}

Number of lamellae in niosomes can be determined by using electron microscope, NMR spectroscopy or X-ray scattering method [44]

\section{5) Membrane rigidity:}

Membrane rigidity of the noisome is measured by means of mobility of fluorescence probe as function of temperature [60].

\section{6) Bilayer formation:}

Assembly of non-ionic surfactants to form bilayer vesicle is characterized by the formation of X-cross under light polarization microscopy [71].

\section{7) Stability study:}

The stability of niosomes can be evaluated by determining mean vesicle size, size distribution, and entrapment efficiency over several month storage periods of niosomal suspension at different temperatures. During storage the niosomes are sampled at regular intervals of time and the percentage of drug which is retained into the niosomes is analyzed by UV spectroscopy or HPLC methods [72].

\section{8) Vesicular surface charge:}

Niosomes are generally prepared by the inclusion of charged molecules in the bilayer to prevent the aggregation of formed vesicles. When dicetyl phosphate like charged molecule was incorporated in vesicles, a reduction in aggregation of vesicle was observed. The charge on vesicles is expressed in terms of zeta potential and calculated using the Henry's equation: [70].

$$
£=\mu E \pi \eta / \Sigma
$$

where,

$$
\begin{aligned}
E & =\text { Zeta potential } \\
\mu E & =\text { Electrophoretic mobility } \\
\mu & =\text { Viscosity of medium } \\
\Sigma & =\text { Dielectric constant }
\end{aligned}
$$

\section{APPLICATIONS OF NIOSOMES:}

\section{1) Targeting of bioactive agents:}

a) To reticulo-endothelial system (RES):

The vesicles are preferentially taken by the cells of RES. It can be used in the treatment of animal tumors known to metastasize to the liver and spleen and in parasitic infestation of liver.

b) To organs other than RES:

It has been suggested that carrier system system reaches at specific site in the body by the use of antibodies. Immunoglobulin is a convenient means for targeting of drug carrier [73].

\section{2) For the treatment of Leshmaniasis:}

Leishmaniasis is a disease state in which the parasite invades cells and liver. Antimonials are most commonly preferred drugs. The antimony study was done on mice and it was concluded that increased sodium stibogluconate efficacy of niosomal formulation, effect of two dose on successive days was additive. Niosomes are also effective as liposomes of loaded drug in experimental leishmaniasis [74]. 


\section{3) Tumor targeting:}

For effective cancer chemotherapy, a high concentration of anticancer agent is required at the tumor site. This minimizes the concentration of the drug in other tissue compartments of the body, thus minimizing their adverse reactions. Niosomes have been studied by several groups for enhanced delivery of anticancer agents to regional lymphatics prepared niosomes of cytarabine hydrochloride by lipid hydration method that excluded dicetyl phosphate to obtain vesicles of smaller size. The size of the vesicles obtained ranged from 600 to $1000 \mathrm{~nm}$. Among the different surfactants selected (Span 60, Span 80, Tween 20, Tween $80)$, Span 60 formulation yielded the slowest release rate. Release occurred in two phases, an initial burst release that lasted for 2-6h, followed by a sustained release that was maintained for at least $16 \mathrm{~h}$ [75].

\section{4) For the treatment of AIDS:}

AIDS is caused by human immunodeficiency virus (HIV), which is characterized by severely damaged immune system. Zidovudine (AZT) is anti-HIV compound which is used for AIDs treatment. It is given alone or in combination with antiviral drugs. In one of the study, the noisome made by addition of Tween 80 showed high entrapped amount of AZT drug and addition of diacetyl phosphate increased the drug release for prolonged time (88.72\% over 12 hours). During preparation of niosomes, the molecular ratios of non-ionic surfactant with constant ratio of cholesterol, the entrapment efficiency was changed and controlled release of AZT was observed [76].

\section{5) Niosome as carrier for haemoglobin:}

Niosomes are used as carrier for haemoglobin. Vesicles are easily permeable to oxygen and haemoglobin curve can be modified similarly to non-capsulated haemoglobin. Niosomal suspension shows a visible spectrum which is superimposable onto that of free haemoglobin [53].

\section{6) Antibiotics:}

The non-ionic surfactant vesicles (niosomes) are used as carrier for ophthalmic delivery of a water soluble local antibiotic. Gentamicin sulphate was investigated and results demonstrated that niosomes are the promising ophthalmic carriers for topical application of gentamicin sulphate [77].

\section{7) Protein and peptide:}

Niosomes can be established as sustain release oral formulation for transport of peptide and protein [78].

\section{8) Transdermal delivery:}

Niosomes as a transdermal drug delivery systems was studied and also their ability to enhance drug permeation and reduce skin irritation through the intact stratum corneum was also studied. Permeation of ketorolac (a potent NSAID) across excised rabbit skin from various proniosome gel formulation was investigated using Franz diffusion cells. The prepared proniosomes significantly improved drug permeation and reduced and reduced lag time [79].

\section{FUTURE PROSPECTS:}

Niosome is a promising drug delivery system. Noisome can be used to encapsulate toxic drugs like anti-cancer, antiviral, anti-AIDs etc and can increase their bioavailability and targeting properties. Special storage and handling conditions are not required for niosomes.

\section{CONCLUSION:}

Niosomes represent a promising and novel drug delivery technology. They are drug carriers to design effective drug delivery system. They offer a great opportunity for loading hydrophilic, lipophilic or both drugs together. Many studies have been demonstrated that niosomes improve the stability of entrapped drug, reduce the dose and enable targeted delivery to a specific site. Niosomes appears to be well preferred drug delivery system over liposome as niosomes are stable and economic. This system is widely accepted by the researchers as well as academicians. Niosomes have a great drug delivery potential for targeted delivery of anticancer, anti-infective, anti-inflammatory agents, transdermal drug delivery and recently as vaccine adjuvant and as diagnostic agents.

\section{REFERENCES:}

1. Jeganath $S$, Nitish B, Khalifa FKA. Niosomes as target drug delivery system: A Review. Int. J. Res. Pharm. Sci, 2020; 11(3): 3198-3203.

2. Baillie AJ, Florence AT, Hume LR, Muirhead GT, Rogerson A. The preparation and properties of niosomes-non-ionic surfactant vesicles. Journal of Pharmacy and Pharmacology, 1985; 37(12): 863-868.

3. Madhav NVS, Saini A. Niosomes: a novel drug delivery system. International Journal of Research in Pharmacy and Chemistry, 2011; 1(3): 498- 511.

4. Allen TM. Liposomal drug formulations: Rationale for development and what we can expect for the future. Drugs, 1998; 56(5): 747-756.

5. Handjani-Vila RM, Ribier A, Rondot B and Vanlerberghie G. Dispersions of lamellar phases of nonionic lipids in cosmetic products. Int. J. Cos. Sci, 1979; 1:303-314.

6. Kemps $\mathrm{J}$ and Crommelin DA. Hydrolyse van fosfolipiden in watering milieu. Pharm Weekbl, 1998; 123: 355-363.

7. Rai AK, Alam G, Singh AP and Verma NK. Niosomes: An approach to current drug delivery-a Review. International Journal of Advances in Pharmaceutics, 2017; 6(2): 41-48.

8. Kaur D, Kumar S. Niosomes: present scenario and future aspects. Journal of Drug Delivery \& Therapeutics, 2018; 8(5): 35-43.

9. Syeda SF, Shireen B, Talath F, Madiha J. Niosomes as nanoparticular drug carriers. Ijppr.Human, 2017; 9(3): 117-133.

10. Keshavshetti GG, Shirsand SB. Recent advances in niosomal drug delivery - a review. Research Journal of Life Sciences, Bioinformatics, Pharmaceutical and Chemical Sciences, 2019; 5(3): 514-531.

11. Sanklecha VM, Pande VV, Pawar SS, Pagar OB and Jadhav AC. Review on Niosomes. Austin Pharmacol Pharm., 2018; 3(2): 1-7.

12. Gurjar P, Naik N, Chouksey S. Niosome: a promising pharmaceutical drug delivery. Int. J. Pharm. Anal., 2014; 2(5): 425-431.

13. Kalra N, Jeyabalan G. Niosomes: A versatile drug delivery system. Research Journal of Life Sciences, Bioinformatics, Pharmaceutical and Chemical Sciences, 2016; 2(4): 44-54.

14. Bhat MI, Ganesh NS, Majeed T and Chandy V. Niosomes a controlled and novel drug delivery system: A brief review. World journal of Pharmaceutical sciences, 2019; 3(8): 481-497.

15. Usman MRM, Ghuge PR and Jain BV. Niosomes: a novel trend of drug delivery. European Journal of Biomedical and Pharmaceutical Sciences, 2017; 4(7): 436-442.

16. Sharma D, Ali AAE, Aate JR. Niosomes as novel drug delivery system: review article. PharmaTutor, 2018; 6(3): 58-65.

17. Sudheer P, Kaushik K. Review on niosomes - a novel approach for drug targeting. Journal of Pharmaceutical Research, 2015; 14(1): 20-25.

18. Hadjizadeh A, Moghassemi S. Nano-niosomes as nanoscale drug delivery systems: an illustrated review. Journal of Controlled Release, 2014; 185: 22-36.

19. Zhang S, Morris ME. Efflux transporters in drug excretion. In: Wang B, Siahaan T, Soltero R, editors. Drug Delivery: Principles and Applications, New Jersey, John Wiley \&Sons publishers, 2005 .p. 381-398.

20. Bhatt P, Lalani R, Vhora I, Patil S, Amrutiya J, Misra A, et al. Liposomes encapsulating native and cyclodextrin enclosed 
paclitaxel: Enhanced loading efficiency and its pharmacokinetic evaluation. International journal of pharmaceutics. 2018;536(1):95-107.

21. Shtil AA, Grinchuk TM, Tee L, Mechenter EB, and Ignatova TN Overexpression of P-glycoprotein is associated with a decreased mitochondrial transmembrane potential in doxorubixin selected K562 human leukemia cells. International Journal of Oncology, 2000; 17: 387-392.

22. Kumar SD, Agarwal S, Sheikh MM, Raveendran S, Rochani AK, Maekawa T. Formulation, characterization and evaluation of morusin loaded niosomes for potentiation of anticancer therapy. Royal Society of Chemistry Advances, 2018; 8: 3262132636.

23. Amoabediny G, Naderinezhad S, Haghiralsadat F. Co-delivery of hydrophilic and hydrophobic anticancer drugs using biocompatible $\mathrm{pH}$-sensitive lipid-based nano-carriers for multidrug-resistant cancers. Royal Society of Chemistry Advances, 2017; 7: 30008-300019.

24. Ueda K, Okamura N, Hirai M, Tanigawara Y, Saeki T,Kioka N, Komano $\mathrm{T}$ and Hori R. Human P-glycoprotein transports cortisol, aldosterone, and dexamethasone, but not progesterone. The Journal of Biological Chemistry, 1992; 267(34): 2424824252.

25. Greenblatt DJ, Perloff MD, Moltke LLV, Marchand JE. Ritonavir induces P-glycoprotein expression, multidrug resistance associated protein (MRP1) expression, and drug transporter mediated activity in a human intestinal cell line. Journal of Pharmaceutical Sciences, 2001; 90(11): 1829-1837.

26. Kumar GP, Rajeshwarrao P. Nonionic surfactant vesicular systems for effective drug delivery-an overview. Acta Pharmaceutica Sinica B, 2011; 1(4):208-219.

27. Uchegbu IF, Vyas SP. Non-ionic surfactant based vesicles (niosomes) in drug delivery. International Journal of Pharmaceutics, 1998; 172: 33-70.

28. Uchegbu IF, Florence AT. Non-ionic surfactant vesicles (niosomes): physical and pharmaceutical chemistry. Advances in Colloid Interface Science, 1995; 58:1-55.

29. Florence AT, Arunothayanun P, Bernard MS, Craig DQM, Uchegbu IF.The effect of processing variables on the physical characteristics of non-ionic surfactant vesicles (niosomes) formed from a hexadecyl diglycerol ether. International Journal of Pharmaceutics, 2000; 201:7-14.

30. Tripathi $P$, Bhardwaj $P$, Gupta R, Pandey S. Niosomes: A review on niosomal research in the last decade. Journal of Drug Delivery Science and Technology, 2020; 56:1-17.

31. Nasir A, Harikumar SL and Kaur A. Niosomes: An excellent tool for drug delivery. International Journal of Research in Pharmacy and Chemistrys, 2012; 2(2): 479-487.

32. De S, Girigoswami A, Das S. Fluorescence and dynamic light scattering studies of niosomes membrane mimetic systems. Spectrochimica Acta Part A, 2006; 64: 859-866.

33. Rogerson A, Cummings J, Florence AT. Adriamycin-loaded niosomes-drug entrapment, stability and release. Journal of Microencapsulation, 1987; 4(4): 321- 328.

34. Cummings J, Rogerson A, Florence AT, Willmott N. The distribution of doxorubicin in mice following administration in niosomes. J. Pharm. Pharmacol., 1988; 40: 337-342.

35. Louis D, Mahmoud K, Mohamed M and Ibrahim A. An overview on niosomes: a drug nanocarrier. Drug Designing and Intellectual Properties International Journal, 2018; 1(5): 143151.

36. Uchegbu IF, Lalatsa A, Wong D (2013). Polymeric nanoparticles. In: Uchegbu IF, Schatzlein AG, Cheng WP and Lalatsa A editors. Fundamentals of pharmaceutical nanoscience, Springer, New York, USA Publishers, .p. 211-234.

37. Khan R, Irchhaiya R. Niosomes: a potential tool for novel drug delivery. Journal of Pharmaceutical Investigation, 2016; 46(3): 195-204.

38. Dwivedi C, Kumar B, Tiwari SP, Satapathy T, Yadav R, Sahu G, Roy A. Niosomes: an excellent tool for drug delivery. Int.J.of Res. in Pharmacology and Pharmacotherapeutics, 2014; 3(3): 192204.

39. Cetinel S, Zarrabi A, Durak S, Rad ME, Yetisgin AA, Sutova HE and Kutlu 0 . Niosomal drug delivery systems for ocular disease-recent advances and future prospects. Nanomaterials, 2020; 10(6): 1-29.
40. More VV, Gilhotra RM, Manoj M. Nitalikar, Prajakta K. Khule. Niosomal drug delivery - a comprehensive review. Asian Journal of Pharmaceutics, 2018; 12(4): 1159-1164.

41. Baillie AJ, Coombs GH, Dolan TF, Laurie J. Non-ionic surfactant vesicles, niosomes, as a delivery system for the anti-leishmanial drug, sodium stibogluconate. J. Pharm Pharmacol., 1986; 38: 502-505.

42. Chavda VP. Niosome: a vesicular weapon for targeted and controlled drug delivery. Indian Journal of Novel Drug Delivery, 2016; 8(3): 133-156.

43. Frank LS and Huang L. Large scale production of DC-Chol cationic liposomes by microfluidization. International Journal of Pharmaceutics, 1996; 144(2): 131-139.

44. Gowda DV, Jain SC, Gupta NV, Kulkarni PK. A brief review on niosomes. Journal of Pharmacy Research, 2017; 11(5): 450-458.

45. Raja NR, Pillai GK, Udupa N, Chandrashekar G. Antiinflammatory activity of niosome encapsulated diclofenac sodium in arthritic rats. Indian Journal of Pharmacology, 1994; 26(1): 46-48.

46. Sunilkumar MR, AdlinJinoNesalin J, Man TT. Niosome as a novel drug delivery system-review. Internationa Research Journal of Pharmaceutical and Applied Siences, 2015; 5(3): 1-7.

47. Lohumi A, Rawat S, Sarkar Si, Sipai AB, Yadav MV. A novel drug delivery system: niosomes review. Journal of Drug Delivery \& Therapeutics, 2012; 2(5): 129-135.

48. Mayer LD, Bally MB, Hope MJ, Cullis PR. Uptake of antineoplastic agents into large unilamellar vesicles in response to a membrane potential. Biochem Biophys Acta, 1985; 816(2): 294302.

49. Kuotsu K, Karim MK, Mandal AS, Biswas N, Guha A, Chatterjee S, Behera M. Niosome: a future of targeted drug delivery systems. J Adv Pharm Tech Res., 2010; 4(1): 374-380.

50. Navya MN, Parthiban S, Neasalin JAJ, Vikneswari A. Niosomes as novel vesicular drug delivery system- a review. Asian Journal of Research in Biological and Pharmaceutical Sciences, 2014; 2(2): 62-68.

51. Chauhan S, Luorence MJ. The preparation of polyoxyethylene containing non-ionic surfactant vesicles. J Pharm Pharmacol. 1989; 41(6)

52. Yuan WE, Xuemei Ge, Minyan Wei, Suna H. Advances of nonionic surfactant vesicles (niosomes) and their application in drug delivery. Pharmaceutics, 2019; 11(2): 1-16.

53. Yadav JD, Kulkarni PR, Vaidya KA, Shelke GT. Niosomes: a review. Journal of Pharmacy Research, 2011; 4(3): 632-636.

54. Khanam N, Alam MI, Sachan AK, Gangwar SS, Sharma R. Recent trends in drug delivery by niosomes: a review. Asian Journal of Pharmaceutical Research and Development, 2013; 1(3): 115122.

55. Sudhamani T, Priyadarisini N, Radhakrishnan M. Proniosomes a promising drug carriers. International Journal of PharmTech Research, 2010; 2(2): 1446-1454.

56. Almira I, Blazek-Welsh, Rhodes DG. Maltodextrin-Based Proniosomes. AAPS Pharm SciTec., 2001; 3(1): 1-8.

57. Blazek-Walsh AI and Rhodes DG. SEM imaging predicts quality of niosomes from maltodextrin-based proniosomes. Pharmceutical Research, 2001; 18: 656-661.

58. Gandhi M, Paralkar S, Sonule M, Dabhade D and Pagar S. Niosomes: novel drug delivery system. International Journal of Pure and Applied Bioscience, 2014; 2(2): 267-274.

59. Akhilesh D, Kamath JV. Review on span-60 based non-ionic surfactant vesicles as novel drug delivery. International journal of research in pharmaceutical and biomedical sciences, 2012; $3(1): 6-12$

60. Nagalakshmi, Aruljothy M, Shanmuganathan S. An overview on niosome as carrier in dermal drug delivery. Journal of Pharmaceutical science and Research, 2015; 7(11): 923-927.

61. Sharma P, Jain AP, Pandey P, Gupta R, Roshan S. Niosome a novel approach for drug delivery system: an overview. Asian Journal of Pharmaceutical science and Research, 2013; 3(5):1830.

62. Cummings J, Staurt JF, Calman KC. Determination of adriamycin, adriamycinol and their 7- deoxyaglycones inhuman serum by high performance liquid chromatography. Journal of Chromatography, 1984; 311: 125-33.

63. Vadlamudi $\mathrm{CH}$, Sevukarajan M. Niosomal drug delivery systema review. Indo American Journal of Pharmceutical Research, 2012; 2(9). 
64. Nasseri B. Effect of cholesterol and temperature on the elastic properties of niosomal membranes. International Journal of Pharmaceutics, 2005; 300: 95-101.

65. Mahale NB, Thakkar PD, Mali RG, Walunj DR, Chaudhari SR. Niosomes: novel sustained release nonionic stable vesicular systems - an overview. Advances in Colloid and Interface Science, 2012; 183-184: 46-54.

66. Sarker A, Shimu IJ, Alam SAA. Niosome: as dermal drug delivery tool. IOSR Journal of Pharmacy and Biological Science, 2015; 10(2): 73-79.

67. Sakthivel M, Kannan K, Manavalan, Senthamarai. Non-ionic surfactant vesicles-a review. Research Journal of Pharmaceutical, Biological and Chemical, 2012; 3(1):604-614.

68. Jindal K. Niosomes as a potential carrier system: a review. International Journal of Pharmaceutical, Chemical and Biological Sciences, 2015; 5(4): 947-959.

69. Carafa M, Marianecci C, Marzio LD, Rinaldi F, Celia C, Donatella Paolino D, Alhaique F, Esposito S. Niosomes from 80s to present: the state of the art. Advances in Colloid and Interface Science, 2014; 205: 187-206.

70. Singh SK, Rajera R, Nagpal K, and Mishra D. Niosomes: a Controlled and novel drug delivery system. Biological and Pharmaceutical Bulletin, 2011; 34(7): 945-953.

71. Gandhi A, Sen SO, Paul A. Current trends in niosome as vesicular drug delivery system. Asian Journal of Pharmacy and Life Science, 2012; 2 (2): 339-353.

72. Stahl F, Seleci DA, Seleci M, Walter JG, and Scheper T. Niosomes as nanoparticular drug carriers: fundamentals and recent applications. Hindawi Publishing Corporation Journal of Nanomaterials, 2016; 2016: 1-13.

73. Mujoriya R, Bodla RB, Dhamande K, Singh D and Patle L. Niosomal drug delivery system: the magic bullet. Journal of Applied Pharmaceutical Science, 2011; 1(9): 20-23.

74. Kalra N, Jeyabalan G, Singh G, Choudhary S. Non- ionic surfactant vesicles and their therapeutics potentials. Journal of Innovations in Pharmaceuticals and Biological sciences, 2016; 3 (2): 193-201.

75. Azeem A, Anwer MK and Talegaonkar S. Niosomes in sustained and targeted drug delivery: some recent advances. Journal of Drug Targeting, 2009; 17(9): 671-689.

76. Koh RY, Yeo PL, Chye SM and Ling APK. Niosome: a mini review on its structure, properties, methods of preparation and medical applications. Journal of Chemical and Pharmaceutical Research, 2016; 8(10): 231-239.

77. Pawar P, Sankhyan A. Recent trends in niosome as vesicular drug delivery system. Journal of Applied Pharmaceutical Science, 2012; 2(6): 20-32.

78. Lalani R, Misra A, Amrutiya J, Patel H, Bhatt P, Patel V. Challenges in Dermal Delivery of Therapeutic Antimicrobial Protein and Peptides. Current Drug Metabolism. 2017; 18(5):426-36.

79. Abdelkader H, Alani AWG and Alany RG. Recent advances in non-ionic surfactant vesicles (niosomes): self-assembly, fabrication, characterization, drug delivery applications and limitations. Drug Delivery, 2013; 21(2): 87-100. 